\title{
Book review of Land Use Transitions and Rural Restructuring in China by Hualou Long
}

\section{WOODS Michael}

Department of Geography and Earth Sciences, Aberystwyth University, Aberystwyth SY23 3DB, UK

The restructuring of rural China is one of the most important elements of global social and economic change in the early twenty-first century. From a traditionally rural country, with deep cultural roots in the 'soil', China has been transformed into a highly advanced and largely urbanized society within the course of a few decades. The scale and significance of the transformation is equivalent to the industrialization and urbanization of Europe in the nineteenth and early twentieth centuries, and like the European experience a century earlier, its impacts reverberate around the globe. Yet, contemporary China is not Victorian-era Europe and whilst there are parallels, we cannot assume that the trajectories, consequences and responses are the same.

The shifting rural-urban dynamics of contemporary China are not just a question of population movement or land use change, but are entangled with a much wider series of social, economic, cultural, environmental and political issues. Urbanization and rural restructuring raise particular challenges for the governance of an increasingly mobile population and asymmetrical workforce, the allocation of public resources, the reduction of territorial inequalities, the maintenance of food security, and the management of the environmental impacts of development. These challenges have been recognized by the Chinese government, with the policies of 'Building the New Socialist Countryside' since 2006 and subsequent 'Rural Vitalization' since 2017 adopted as a top priority for the Communist Party of China and forming arguably the most ambitious programme of rural development and regeneration ever attempted anywhere in the world.

China's rural-urban transformation therefore inevitably demands scientific investigation. Initially, geographers and other social scientists were drawn to China's rapidly expanding cities as the focus of their studies; however over the last decade researchers have increasingly explored the problems of the rural districts of China and the processes of restructuring that are experienced there. Accordingly, there has been an explosion in the number of published papers on rural China, by both Chinese and international scholars, appearing in leading international journals. Indeed, so extensive now is this literature that there is a desperate 
need for a coherent and accessible overview text to help students and researchers to navigate the field.

In Land Use Transitions and Rural Restructuring in China, Hualou Long provides just such a guide. The book discusses the considerable evidence base accumulated by Long's extensive body of research on rural China over more than a decade, and draws on his training in both human and physical geography, his experience of working in both policy and academic contexts, and his detailed knowledge of international debates and concepts in rural studies. It presents a rich blend of national and regional scale statistical analysis with detailed local case studies, combining quantitative and qualitative data and adding sophisticated critical and theoretically-informed analysis that both acknowledges historical trends and looks ahead to future projections. Together these elements make for an authoritative and important volume.

The chapters of this book emphasize the key components of China's rural transition, starting with the central significance of land. Land is important as a contested resource, with the conversion of rural land for urban expansion and housing development needing to be balanced against the preservation of farmland to ensure food security for China's expanding population. Achieving this balance requires new approaches to land management, and may in places involve changes in land tenure and the consolidation of traditional units into larger holdings. It also leaves little room for the neglect or abandonment of land, especially in densely-packed Eastern Coastal China. In 'hollowed villages' such as those discussed in Chapter 3, land consolidation and reorganization is frequently a vital response to out-migration and the disuse of properties, necessary to ensure the continuing coherence and viability of the communities and to keep good agricultural land in productive use.

At the same time, the place of people in China's rural transition is not over-looked, with Chapter 6 for example drawing attention to the changing profile of the rural population and rural labour force, with out-migration of working-age individuals contributing both to a social problem of 'left-behind' aged communities and an economic problem of a lack of skilled workers. The third key dimension is therefore that of the economy. Revitalizing rural China requires the modernization and diversification of its economy and as the examples in Chapter 8 show this is taking many different forms, from industrial agriculture to eco-tourism to the growing opportunities offered by e-commerce and the proliferation of Taobao villages. Characteristically, Long's analysis of localities following these different trajectories not only unpicks the different drivers but also focuses in detail on the impacts, including changes in land use in the villages concerned. As such, the various case studies presented in this volume aggregate into an integrated and holistic picture of change in rural China.

Underlying the three dimensions of land, people and economy is the significance of policy. As noted above, the restructuring of rural China described in this book has been shaped not only by the centripetal force of urbanization, but also the Chinese state's response to urbanization in the policies of 'Building the New Socialist Countryside' and 'Rural Vitalization'. As a recurrent thread through the chapters, Long describes and evaluates policy interventions, but also discusses the ways in which policy and the roles and practices of central, provincial and local governance have evolved, noting for instance the changing contours of state intervention in Chapter 13. Neither is this the perspective of a disinterested bystander, as Long reflects on the role of science - including his own research - in informing the development and application of evidence-based policy for rural China. 
As a geographical account, Land Use Transitions and Rural Restructuring in China also emphasizes the spatial variations in the experiences of restructuring in different parts of the Chinese countryside. Rural restructuring is different in densely-populated Eastern Coastal China than in more sparsely populated regions of Northern or Western China; and it is different in the peri-urban zones on the edge of mega-cities than in remote rural settlements. These differences are demonstrated in the book through GIS analysis and mapping of trends and outcomes across the country as well as in comparisons between individual case studies. For explanation, we need to recall the vast size of China and the difficult nature of much of its physical terrain, as well as to examine and consider the continuing importance of local traditions, cultural variations between provinces, and the role of local agency and the degree of discretion of local governance actors - which sometimes surprises international observers who perceive China as a centralized state.

At the same time, the book reinforces the embeddedness of all parts of rural China in a complex web of interconnections that link the rural and the urban, and indeed, the rural and the rural - a map of e-commerce sales from Xiaying illage in Hubei Province in Chapter 8 being one striking example. Moreover, in the final chapter Long positions rural restructuring in China in the broader context of globalization. This is a dynamic that I have myself examined in research in China for the European Research Council GLOBAL-RURAL, in which I was privileged to collaborate with Hualou and his colleagues at Institute of Geographic Sciences and Natural Resources Research. In case studies of craft revitalization in Shandong Province, labour out-migration and return investment in Henan Province, and manufacturing and tourism in Zhejiang Province, I observed dramatic transformations of rural communities that were taking place against the backdrop of a globalizing economy and society, but which represented, to adapt Jeffrey Henderson's term, 'globalization with Chinese characteristics'. Rural communities in China are, as yet, protected from the more aggressive aspects of globalization, such as competition from imports in unregulated markets and speculative foreign investment, whilst China's unique form of community capitalism and labour force management have enabled some rural localities to exploit opportunities in the global economy for community gain. Equally, if globalization is understood as the multiplication, intensification and acceleration of relations between places, then increased interconnectivity within China might be the form that it is most commonly experienced by rural communities rather than through international connections - inter-provincial connections in China being arguably the equivalent of cross-border links in Europe, which are often uncritically regarded as expressions of globalization.

These last observations highlight the paradoxical nature of contemporary rural restructuring in China - that it must be understood in global context and has parallels with both present-day and historic processes elsewhere in the world, but is also distinctive and different which has implications for how we study it as social scientists. Concepts derived from western literature, such as 'rural restructuring' and 'governance' can help to illuminate aspects of the experience of change in rural China and have been valuably employed to develop a more critical perspective and to engage with international debates; yet not all concepts are transferable, and we urgently need rural geography that is written from China articulating explanations and formulating concepts that are rooted in empirical research on the Chinese experience. This book is an important contribution to building this new literature. 